\title{
EDITORIAL
}

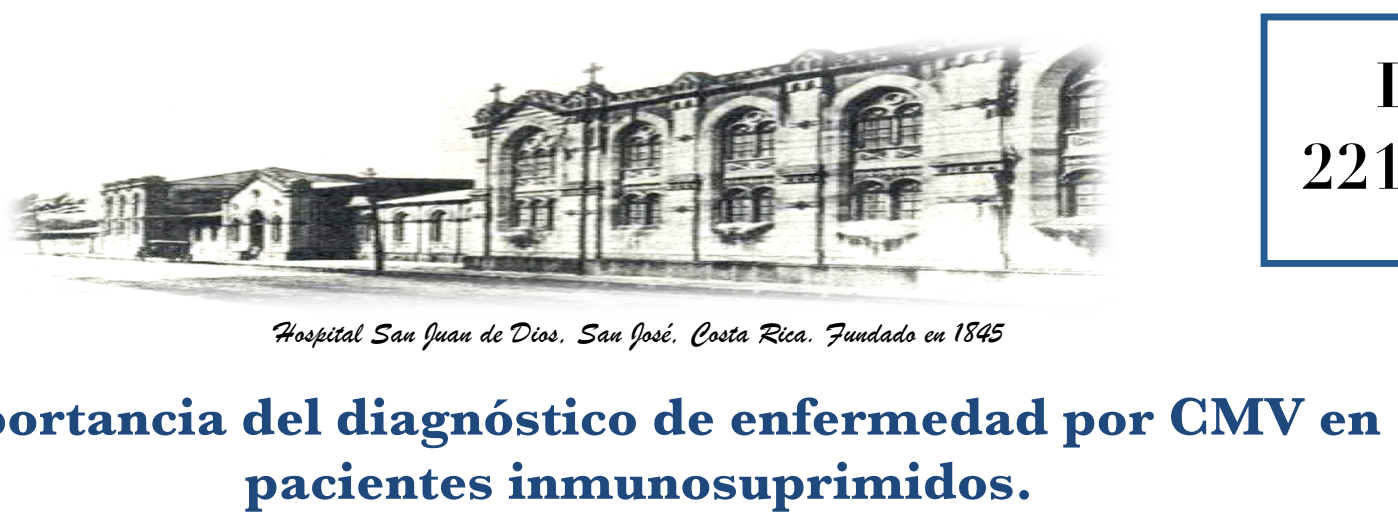

Recibido: $\quad 17 / 07 / 2012$

Aceptado: $\quad 18 / 07 / 2012$

\section{Importancia del diagnóstico de enfermedad por GMV en pacientes inmunosuprimidos.}

HSJD

Ibrahim Barguil Meza ${ }^{1}$

\footnotetext{
${ }^{1}$ Especialista en Medicina Interna. Jefe del Servicio de Medicina 1 HSJD. Profesor Interino Licenciado de la Cátedra de Medicina Interna, UCR-HSJD. Profesor del posgrado de Medicina Interna UCRCENDEISSS. Correo electrónico: ibarguil@ccss.sa.cr
}

En este número presentamos una excelente revisión de infecciones por Citomegalovirus, que ejemplifica de una manera muy completa los nuevos retos que enfrenta el clínico al enfrentarse a una gran cantidad de pacientes con condiciones asociadas a alteraciones de la inmunidad celular, tal como se ve en el feto que tiene inmadurez del sistema inmunológico, pacientes con infección por VIH, pacientes con uso de drogas inmunosupresoras en general, pacientes con cáncer, estados de desnutrición severa o pacientes trasplantados.

Estas condiciones de riesgo, cada vez con una sobrevida mayor y que se presentan en forma creciente en nuestros servicios, representan un problema diagnóstico, ya que por su inmunocompromiso, las infecciones se presentan de una manera mas grave o en forma atípica. Debido a este hecho, es de rescatar los nuevos métodos de detección de la enfermedad aguda por Citomegalovirus, por medio de RCP (reacción en cadena de la polimerasa) que es un método sensible y específico, así como la determinación de la avidez de la inmunoglobulina $\mathrm{G}$ ( $\mathrm{IgG})$ que ayuda a diferenciar las infecciones agudas de los falsos positivos.

En otras ediciones, trataremos de ampliar sobre los nuevos métodos de laboratorio y gabinete, así como discutir la sensibilidad y especificidad de los mismos, en el trabajo diagnóstico de otras infecciones oportunistas. 